\title{
Guidelines
}

\section{Chinese Expert Recommendation for Diagnosis and Treatment of Massive Hemoptysis}

\author{
Faguang Jin ${ }^{a}$ Qiang $\mathrm{Li}^{\mathrm{b}}$ Chong Bai ${ }^{\mathrm{c}}$ Hongwu Wang ${ }^{\mathrm{d}}$ Shiyue $\mathrm{Li}^{\mathrm{e}}$ \\ Yong Song ${ }^{f}$ Yiming Zeng ${ }^{g}$ Rui Zhou ${ }^{\text {h }}$ Wangping $\mathrm{Li}^{\mathrm{a}}$ Chengping $\mathrm{Hu}^{\mathrm{i}}$ \\ Jie Zhang ${ }^{j}$ Hongmei Zhouk $^{k}$ Haitao Zhang ${ }^{\text {a }}$
}

\begin{abstract}
${ }^{a}$ Department of Respiratory and Critical Care Medicine, Tangdu Hospital, Air Force Medical University, Xi'an, China; ${ }^{b}$ Department of Respiratory and Critical Care Medicine, Dongfang Hospital, Tongji University, Shanghai, China; 'Department of Respiratory Medicine, Changhai Hospital, Naval Medical University, Shanghai, China; ${ }^{\mathrm{d}}$ Department of Respiratory Medicine, Meitan General Hospital, Beijing, China; ${ }^{\mathrm{e}}$ Guangzhou Institute of Respiratory Health, State Key Laboratory of Respiratory Disease, The First Affiliated Hospital of Guangzhou Medical University, Guangzhou, China; ${ }^{f}$ Department of Respiratory Medicine, Jinling Hospital, Nanjing University School of Medicine, Nanjing, China; ${ }^{9}$ Department of Respiratory Pulmonary and Critical Care Medicine, The Second Hospital of Fujian Medical University, Quanzhou, China; hepartment of Respiratory Medicine, The Second Xiangya Hospital, Central South University, Changsha, China; 'Department of Respiration, Central South University Xiangya Hospital, Changsha, China; jDepartment of Respiration, Beijing Tiantan Hospital, Capital Medical University, Beijing, China; ${ }^{k}$ Department of Respiration, Affiliated Zhongshan Hospital of Guangdong Medical University, Guangzhou, China
\end{abstract}

\section{Keywords}

China $\cdot$ Guidelines · Massive hemoptysis

\begin{abstract}
Massive hemoptysis is one of emergency and critical diseases of the respiratory system. The definition of massive hemoptysis has always been different in the literature, which often depends on the quantitative estimation of the amount of hemoptysis, such as the amount of hemoptysis being in the range of 300-600 mL within $24 \mathrm{~h}$, or hemoptysis more than 3 times within 1 week. Each amount of hemoptysis that is greater than $100 \mathrm{~mL}$ can be considered as massive hemoptysis, but the amount of hemoptysis is difficult to accurately estimate. Therefore, massive hemoptysis can be defined as any life-threatening hemoptysis and any hemoptysis that may cause airway obstruction and asphyxia. Massive hemoptysis accounts for approximately $5 \%$ of all hemoptysis
\end{abstract}

\section{KARGER}

(c) 2019 S. Karger AG, Basel

E-Mail karger@karger.com

www.karger.com/res cases and usually indicates the presence of a potentially severe respiratory or systemic disease. The mortality rate of massive hemoptysis is about $6.5-38 \%$. The cause of death is generally shock caused by airway obstruction or excessive bleeding, and asphyxia is the main cause of death. At present, due to insufficient understanding of massive hemoptysis, there are limited technical means in the etiological diagnosis and untimely or improper treatment, resulting in high mortality of massive hemoptysis. Therefore, the diagnosis and treatment of massive hemoptysis needs to be standardized.

(c) 2019 S. Karger AG, Basel

Massive hemoptysis is one of emergency and critical diseases of the respiratory system. The definition of massive hemoptysis has always been different in the literature, which often depends on the quantitative estimation 
of the amount of hemoptysis, such as the amount of hemoptysis is in the range of $300-600 \mathrm{~mL}$ within $24 \mathrm{~h}$, or hemoptysis more than 3 times within 1 week. And each amount of hemoptysis is $>100 \mathrm{~mL}$ can be considered as massive hemoptysis, but the amount of hemoptysis is difficult to accurately estimate [1-4]. Therefore, massive hemoptysis can be defined as any life-threatening hemoptysis and any hemoptysis that may cause airway obstruction and asphyxia $[2,5]$. Massive hemoptysis accounts for approximately $5 \%$ of all hemoptysis cases and usually indicates the presence of a potentially severe respiratory or systemic disease [6]. The mortality rate of massive hemoptysis is about $6.5-38 \%$ [5, 7-12]. The cause of death is generally shock caused by airway obstruction or excessive bleeding, and asphyxia is the main cause of death [13]. At present, due to insufficient understanding of massive hemoptysis, there are limited technical means in the etiological diagnosis and untimely or improper treatment, resulting in high mortality of massive hemoptysis. Therefore, the diagnosis and treatment of massive hemoptysis need to be standardized. The Chinese Medical Association Integrated Respiratory Professional Committee organized relevant domestic experts, combined with clinical experience and related literature, and formulated this specification after finishing discussions.

\section{The Relationship between Pulmonary Vascular Anatomy and Hemoptysis}

The lungs have a dual blood supply from the pulmonary and bronchial arteries [14]. The pulmonary artery originates from the right ventricle, branches into the left and right pulmonary artery, and the pulmonary artery eventually forming a wide capillary network to complete the gas exchange. The pulmonary artery is a low-pressure, low-resistance system with a large blood volume. The blood pressure will not increase significantly even if the blood flow increases. If the pulmonary capillary network ruptures, the amount of bleeding will not be too large, and it is easy to stop bleeding; however, if large pulmonary arteries or branches rupture, hemorrhage often occurs due to large blood volume and short distance from right ventricular, and the success rate of rescue is low. The bronchial artery originates from the aorta, and a few are from the intercostal artery to provide nutrients to the lung parenchyma. Unlike the pulmonary artery, the bronchial artery is a high-pressure system that closely follows the bronchial movement and eventually forms a capillary network in the submucosal layer of the bronchial wall, supplying blood to the bronchial wall. If the bronchial artery ruptures, massive hemorrhage is likely to occur due to high systemic vascular pressure. However, after blood pressure drops due to massive hemorrhage, the amount of bleeding will decrease, providing an opportunity for surgical intervention. As long as the airway is kept unobstructed and there is no asphyxia death, the patient has hope for treatment. It is as clear as possible whether the pulmonary artery is ruptured or the bronchial artery is ruptured, which will be of great help to the treatment of patients and the development of rescue measures.

\section{The Cause of Massive Hemoptysis}

The cause of massive hemoptysis is complicated, and respiratory diseases and systemic diseases can cause massive hemoptysis. Bronchiectasis, tuberculosis, pulmonary aspergillosis, necrotizing pneumonia, cryptogenic hemoptysis, and lung cancer are considered to be the most common causes of massive hemoptysis [5, 7]. Despite of the continuous advancement and development of medicine, up to $20 \%$ of cases have not been found to have obvious causes, and are classified as cryptogenic hemoptysis [7]. With the development of modern medicine, changes in the spectrum of diseases, and the widespread use of antibacterial drugs, the incidence of massive hemoptysis caused by infection is significantly reduced. The common causes of massive hemoptysis are listed in Table 1.

\section{Infection}

In the middle of the 20th century before the advent of anti-TB drugs, TB and its associated complications are the most common cause of hemoptysis. Currently, the rate of massive hemoptysis caused by pulmonary tuberculosis decreased, but it is still common that pulmonary tuberculosis complicated with bronchial tuberculosis results in bronchial damage or bronchiectasis results in hemoptysis [15].

Bronchiectasis and chronic infection are pathological features of bronchiectasia. Repeated bacterial infections, especially Staphylococcus aureus, Pseudomonas aerugino$s a$, and so on, lead to bronchial artery hypertrophy, distortion, aneurysm formation, and systemic circulation pulmonary vascular anastomosis or arterial fistula formation. The above arterial rupture can cause massive, rapid, and fatal massive hemoptysis [16].

In recent years, the proportion of massive hemoptysis caused by fungal infections has gradually increased, espe-
Jin/Li/Bai/Wang/Li/Song/Zeng/Zhou/Li/ $\mathrm{Hu} /$ Zhang/Zhou/Zhang 
cially in patients with cavitary lung disease or with significant immunosuppression. Most of the cavity formations combined with mold infections are Aspergillus infection, and the dilated bronchial artery or intercostal artery is often surrounded by the cavity, which is highly susceptible to rupture and massive bleeding. It has been reported that $50-90 \%$ of Aspergillus infections complicated with cavity can cause massive hemoptysis [17-19]. In addition, mucormycosis infection can also result in massive hemoptysis, mainly because of the characteristics of mucormycosis, which can easily damage the pulmonary artery and cause fatal massive hemoptysis [20-22]. In immunodeficient patients, massive hemoptysis caused by invasive fungal infection is rare, but after the recovery of neutrophil deficiency, increased inflammatory response due to local infection will cause rupture of blood vessels and cause massive hemoptysis [23, 24]. Hemoptysis can also be caused by other lung infections, especially those with lung abscess, and necrotizing pneumonia caused by various infections [25].

\section{Tumor}

Hemoptysis can occur due to any type of lung cancer, and the probability of massive hemoptysis in patients with central airway lumen and tumor cavity formation is high $[5,13,26]$. Squamous cell carcinoma often occurs in the central airway, so the resulting massive hemoptysis is more common than adenocarcinoma, small cell carcinoma, or large cell carcinoma. Any tumor that is transferred to the bronchial cavity or the lung parenchyma can lead to massive hemoptysis. Some new antiangiogenic drugs, such as bevacizumab, can cause tumor necrosis and cavity leading to massive hemoptysis [27].

\section{Autoimmune Diseases}

Autoimmune diseases can also result in massive hemoptysis. The vasculitis also accounts for a proportion of hemorrhage, which can manifest as massive hemoptysis or diffuse alveolar hemorrhage (DAH), and may be accompanied by progressive hypoxemia and respiratory failure, some patients may not have much hemoptysis, even without hemoptysis symptom, but progressive anemia and hypoxemia may occur, with higher mortality [28].

\section{Cardiovascular Disease}

Cardiac hemoptysis is caused by underlying cardiovascular diseases. In diseases that can cause primary cardiogenic hemoptysis, elevated pulmonary venous pressure can lead to venous dilatation/varicose formation,
Table 1. Common causes of massive hemoptysis

\begin{tabular}{|c|c|}
\hline Classification & Disease \\
\hline Infection & $\begin{array}{l}\text { Tuberculosis/nontuberculous mycobacterial } \\
\text { infection } \\
\text { Bronchiectasis (including cystic fibrosis) } \\
\text { Invasive pulmonary fungal disease } \\
\text { Lung abscess } \\
\text { Paragonimiasis } \\
\text { Necrotizing pneumonia } \\
\text { Pulmonary embolism (septic) }\end{array}$ \\
\hline Tumor & $\begin{array}{l}\text { Primary lung cancer } \\
\text { Intratracheal metastatic cancer } \\
\text { Intrapulmonary metastatic carcinoma }\end{array}$ \\
\hline $\begin{array}{l}\text { Autoimmune } \\
\text { disease }\end{array}$ & $\begin{array}{l}\text { Diffuse alveolar hemorrhage } \\
\text { Granulomatous polyangiitis } \\
\text { Microscopic polyangiitis } \\
\text { Goodpasture syndrome } \\
\text { Nodular polyangiitis } \\
\text { Systemic lupus erythematosus } \\
\text { Rheumatoid arthritis } \\
\text { Systemic sclerosis }\end{array}$ \\
\hline $\begin{array}{l}\text { Cardiovascular } \\
\text { diseases }\end{array}$ & $\begin{array}{l}\text { Arteriovenous malformation } \\
\text { Mitral stenosis } \\
\text { Pulmonary embolism/infarction } \\
\text { Congenital heart disease (such as atrial septal } \\
\text { defect, patent ductus arteriosus, etc.) } \\
\text { Primary pulmonary hypertension } \\
\text { Aortic aneurysm } \\
\text { Bronchial arterial fistula } \\
\text { Congestive heart failure } \\
\text { Localized pulmonary venous stenosis after } \\
\text { atrial fibrillation ablation }\end{array}$ \\
\hline Iatrogenic & $\begin{array}{l}\text { Bronchoscopy-related operations } \\
\text { Percutaneous lung biopsy } \\
\text { Pulmonary catheter implantation } \\
\text { Trachea - innominate artery fistula } \\
\text { Radiotherapy } \\
\text { Antiangiogenic drug applications (e.g., } \\
\text { bevacizumab) }\end{array}$ \\
\hline Trauma & $\begin{array}{l}\text { Lung blunt injury } \\
\text { Chest wall penetrating injury } \\
\text { Pseudo-hemoptysis } \\
\text { Bone marrow transplantation }\end{array}$ \\
\hline $\begin{array}{l}\text { Hematological } \\
\text { diseases }\end{array}$ & $\begin{array}{l}\text { Coagulopathy (congenital, acquired, or } \\
\text { iatrogenic) } \\
\text { Platelet disease } \\
\text { Thrombotic thrombocytopenic purpura }\end{array}$ \\
\hline
\end{tabular}

when venous pressure suddenly rises for some reason, it may trigger rupture. Massive hemoptysis may also occur in patients with localized elevation of pulmonary venous pressure caused by local stenosis of the pulmonary vein 
after atrial fibrillation with radiofrequency ablation [29, 30 ], or those with pulmonary arteriovenous malformations $[31,32]$.

\section{Iatrogenic Factors}

Many invasive tests can cause massive hemoptysis due to damage to the pulmonary blood vessels, the main reason being the rupture of the pulmonary or bronchial artery in operation. It is reported that transbronchoscopy, various techniques guided percutaneous puncture biopsy, radioactive particle implantation, percutaneous radiofrequency ablation, and so on had caused massive hemoptysis [33-37]. Patients with long-term tracheostomy may have tracheal-innominate artery fistula, which can cause fatal bleeding $[38,39]$. The insertion position of the tracheal cannula is too low (below the recommended 1-3 tracheal cartilage rings), or the position of the innominate artery is too high to form an innominate arteriovenous fistula of the bronchial artery.

\section{Trauma}

Massive hemoptysis can also occur in patients with chest trauma. A blunt injury can cause airway rupture complicated with pulmonary or bronchial vascular injury [40]. Broken ribs can sometimes result in lung stab wounds, leading to hemoptysis or hemothorax. Similarly, penetrating injuries can also cause lung tears and lung and bronchial vascular damage, causing hemoptysis and/ or hemothorax [41].

\section{Hematological Diseases}

Due to various hematological diseases and bring about primary, secondary, or iatrogenic factors cause coagulopathy, platelet dysfunction, or thrombotic thrombocytopenic purpura can cause hemoptysis or even massive hemoptysis [42-45].

\section{The Diagnosis of Massive Hemoptysis}

\section{Medical History and Physical Examination}

Detailed medical history and comprehensive physical examination are important methods for diagnosing the cause of massive hemoptysis and can provide some key clues for the diagnosis of the cause of massive hemoptysis. Understanding the amount of massive hemoptysis through medical history is very important for an accurate diagnosis. At the same time, clinical evaluation should pay attention to the past history, especially the history of infection, and the history of diseases including respira- tory system, heart disease, autoimmune diseases, and hemorrhagic diseases. Physical examination should carefully record the relevant signs suggesting that the massive hemoptysis originates from the lung and should pay attention to the symptoms of congestive heart failure or malignant tumor. Identify bleeding is from hemoptysis or hematemesis.

\section{Laboratory Inspection}

The initial assessment should include complete laboratory tests such as blood, urine, stool routine, blood type, coagulation function, and liver and kidney function. These tests may indicate the cause of massive hemoptysis, such as coagulation abnormalities, autoimmune pulmonary-renal syndrome. In addition, appropriate laboratory tests should be performed based on the likely etiology.

\section{Imaging Examination}

Imaging examination is the basis of massive hemoptysis diagnosis. Chest X-ray is an important initial evaluation tool, but its false-negative rate is as high as $20-40 \%$. Chest CT scan is the most important imaging method for hemoptysis, and its sensitivity is higher than that of chest radiograph. Enhanced scans can detect pulmonary embolism, arteriovenous malformations, or aneurysms [46]. CT-enhanced development has different phases, and different phases should be used for different purposes. In addition, CT helps to determine which side of the lung the bleeding originates from. However, CT examination has certain limitations for patients with massive hemoptysis. First, it takes time. Second, the patient needs to maintain supine position during operation, which is prone to suffocation. Therefore, acute massive hemoptysis is not suitable for emergency chest CT scans when the patient is at risk.

\section{Bronchoscopy}

For the diagnosis of massive hemoptysis, or poorly treated by conservative medical treatment, it is recommended to perform bronchoscopy early in hemoptysis [47].

\section{Massive Hemoptysis Treatment}

Treatment methods should be based on the etiology of massive hemoptysis, the experience of doctors, and available medical resources. The treatment should be carried out by a multidisciplinary team of doctors in the department of respiratory and critical care medicine, interventional radiology, cardiothoracic surgery, and anesthesiol-
Jin/Li/Bai/Wang/Li/Song/Zeng/Zhou/Li/ $\mathrm{Hu} /$ Zhang/Zhou/Zhang 
Fig. 1. Tumor resection under rigid bronchoscopy. The patient was diagnosed with hemoptysis and found a new spherical neoplasm in the upper segment of the trachea, which grew into the lumen, and the surface was rich in blood supply, which caused bleeding. Rigid argon knife cauterization was used to stop bleeding.
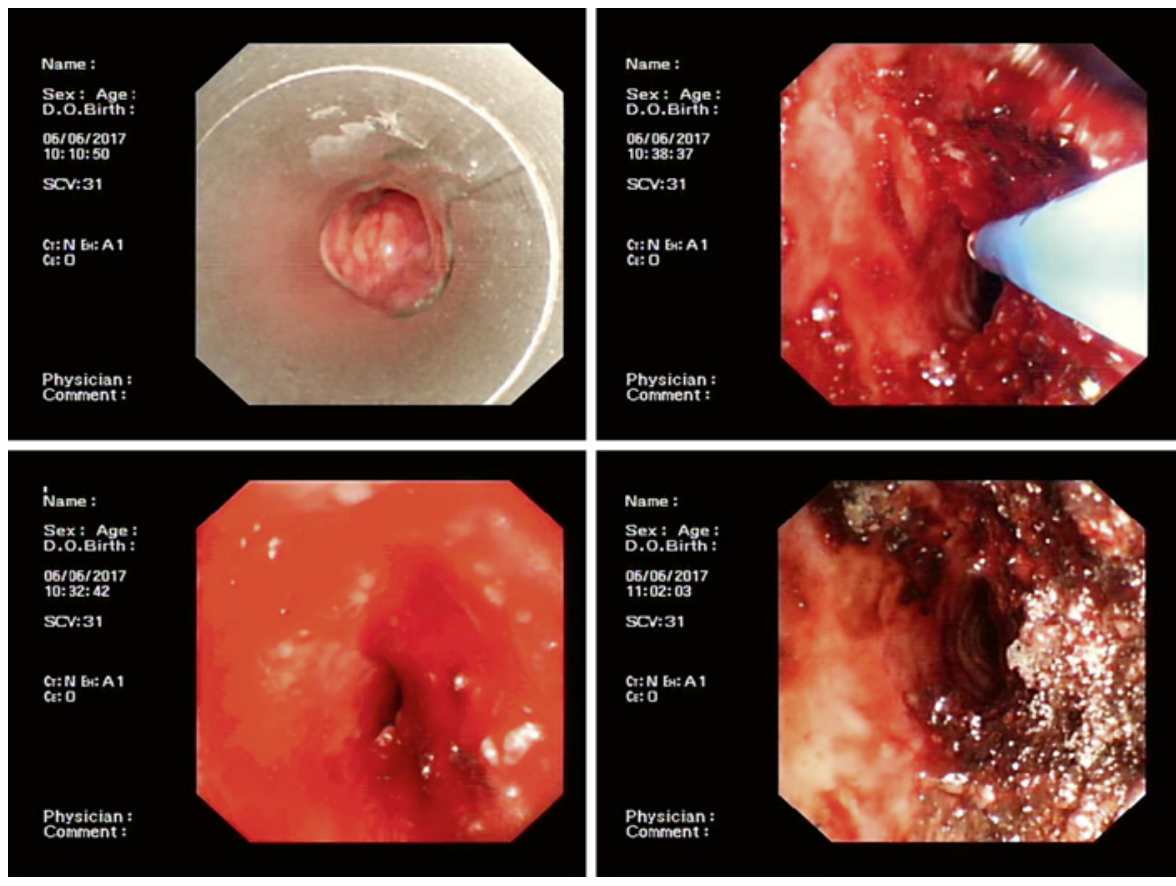

ogy. Bronchoscopy is an important tool for the diagnosis and treatment of massive hemoptysis $[47,48]$. The flexible bronchoscope is convenient to use, but the suction ability is limited, the visual field is easy to be blurred, and for the rapid treatment of massive hemoptysis is limited. The rigid bronchoscope allows for rapid suction while maintaining airway open and ventilated [49]. However, the rigid bronchoscope needs to be performed under general anesthesia, and the operation is complicated, and it is impossible to reach the airway other than the trachea, the bulge, and the main bronchus. Therefore, there are conditions that can be used in combination to achieve optimal diagnosis, evaluation, and control of bleeding effects.

\section{Emergency Treatment Methods}

The principle of emergency treatment of massive hemoptysis is to ensure airway unobstructed and isolate bleeding sources $[13,50-54]$.

\section{Keep the Airway Unobstructed}

When acute active hemorrhage complicated with massive hemoptysis, the best way to clean up the blood and secretions in the airway is the patient's cough reflex. Patients should be encouraged to clear the airway hematocele through the cough. If the patient's cough reflex cannot effectively remove airway hemorrhage, relieve asphyxia, and develop progressive dyspnea or hypoxemia, tracheal intubation should be performed immediately. Large $(8-8.5 \mathrm{~mm})$ catheters used in tracheal intubation with large side holes may be considered for bronchoscopy. If necessary, use a rigid bronchoscope for treatment (Fig. 1).

\section{Isolation of Bleeding Source}

Quickly clean up the hematocele in the airway by tracheal intubation or rigid bronchoscope, isolate the bleeding source as soon as possible to prevent the blood from overflowing into the contralateral to form a blood clot to block the airway and affect the alveolar gas exchange, and keep the airway unobstructed as well. Therefore, in the case of nonbilateral lung bleeding, the first step should be to quickly determine the side of the lung and the lobe from which the bleeding comes and prevent blood from entering the contralateral of the lung, and the most basic method is to let the patient have a lateral position. After finding the source of bleeding, there are several ways to isolate the source of bleeding as much as possible: (1) select a unilateral tracheal intubation under bronchoscopy and insert the distal end of the catheter into the main bronchus of the contralateral lung. The balloon is filled to prevent blood permeation, and the affected side lung is treated under the condition of contralateral lung ventilation. (2) After tracheal intubation, the source of bleeding was identified under bronchoscopy. The Fogarty balloon was placed into the hemorrhagic airway through a bron- 
Fig. 2. Hemostasis by balloon compression. Patients with sudden massive hemoptysis and asphyxia were given tracheal intubation and bronchoscopic suction, followed by balloon compression for hemostasis.
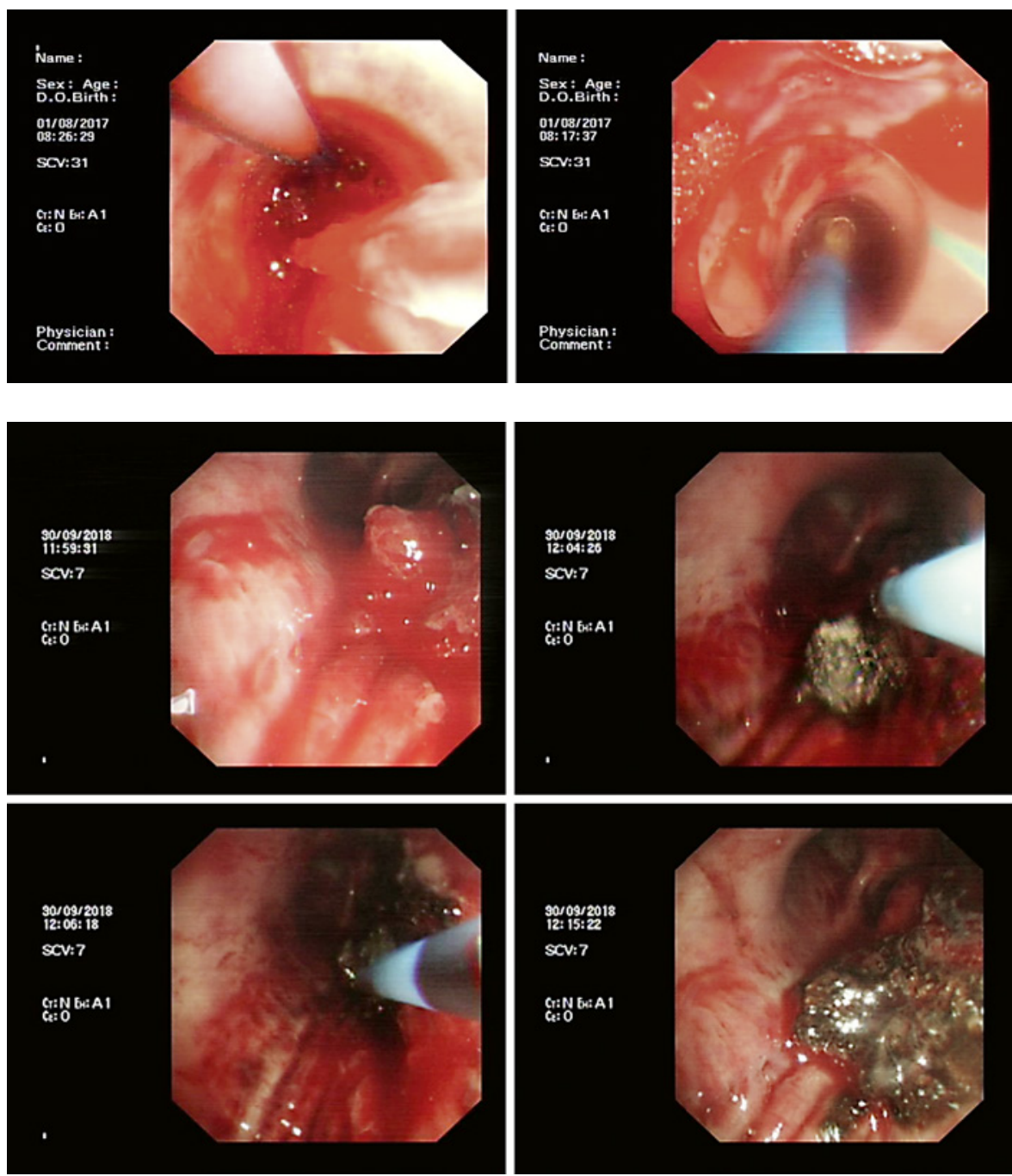

Fig. 3. Stop bleeding by argon knife under bronchoscope. spraying of ice normal saline, diluted adrenaline, thrombin or fibrin complex to contract blood vessels to stop bleeding. (5) When the petechia is directly observed under the bronchoscope, hemostasis can be performed by laser, electric knife, argon knife, or freezing technique (Fig. 2, 3). (6) If the patients are suspected as trachealinnominate artery fistula, emergency surgery should be performed by cardiothoracic surgery. Before the surgical repair, try to cut the trachea, inflate the balloon, or replace the tracheostomy tube with a tracheal intubation catheter, place the distal end of the catheter under the petechia, and inflate the balloon. At the same time, put your finger into the sinus of the tracheotomy and press the anterior wall of the trachea forward to the sternum to help stop bleeding, which will give you time and opportunity for surgery.
Jin/Li/Bai/Wang/Li/Song/Zeng/Zhou/Li/ $\mathrm{Hu} /$ Zhang/Zhou/Zhang 
Fig. 4. Freezing and removing thrombus through bronchoscopy. Patients with massive hemoptysis and respiratory failure were given tracheal intubation and ventilator-assisted breathing. Emergency bronchoscopy revealed that the left main bronchus was blocked by thrombus, the cryoprobe entered the thrombus, pulled out the thrombus, and the removed material showed a bronchial tree-like change. After the removal of 2 thrombus trees, the left main bronchus and the bronchial lumens at all levels were unobstructed.
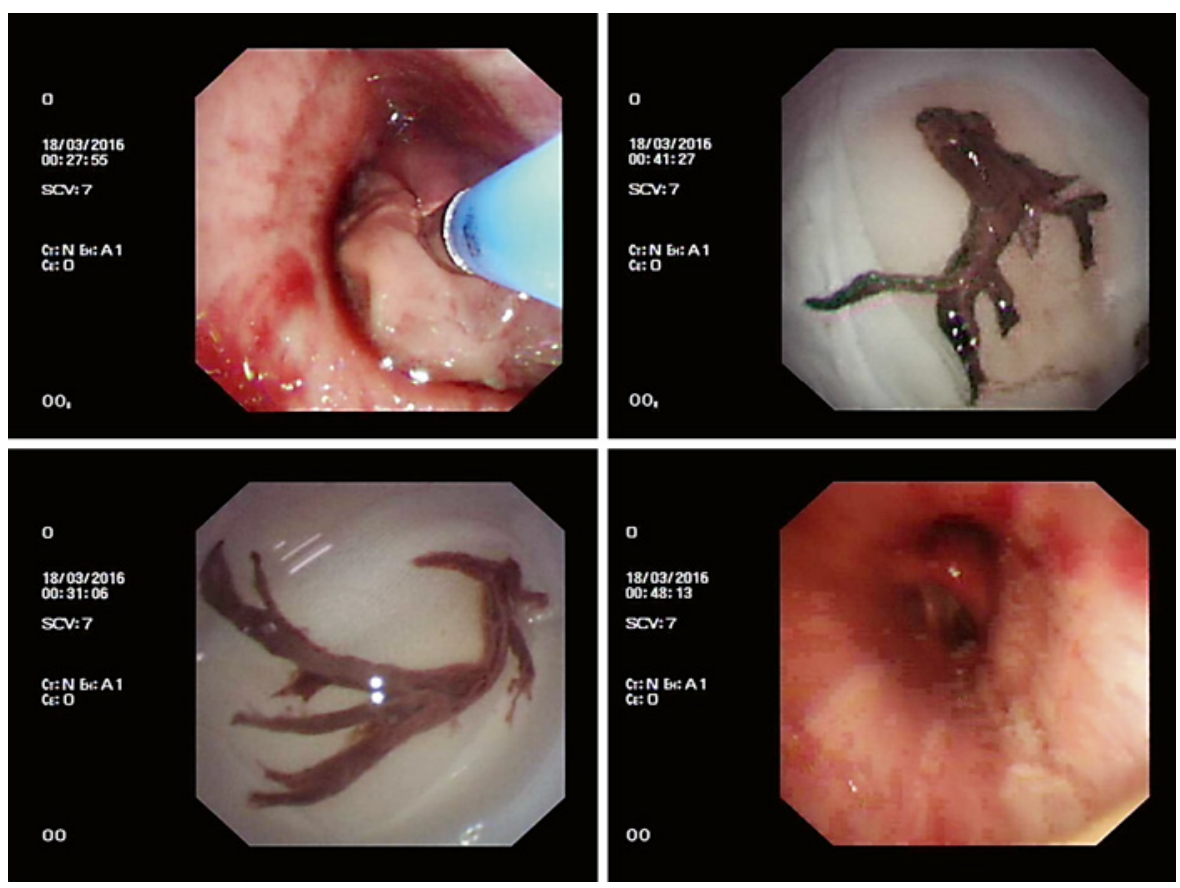

Fig. 5. Bronchial artery DSA angiography after BAE. Patients with massive hemoptysis were given bronchial artery DSA showed contrast agent spillover, after BAE, no development was observed and hemoptysis stopped.
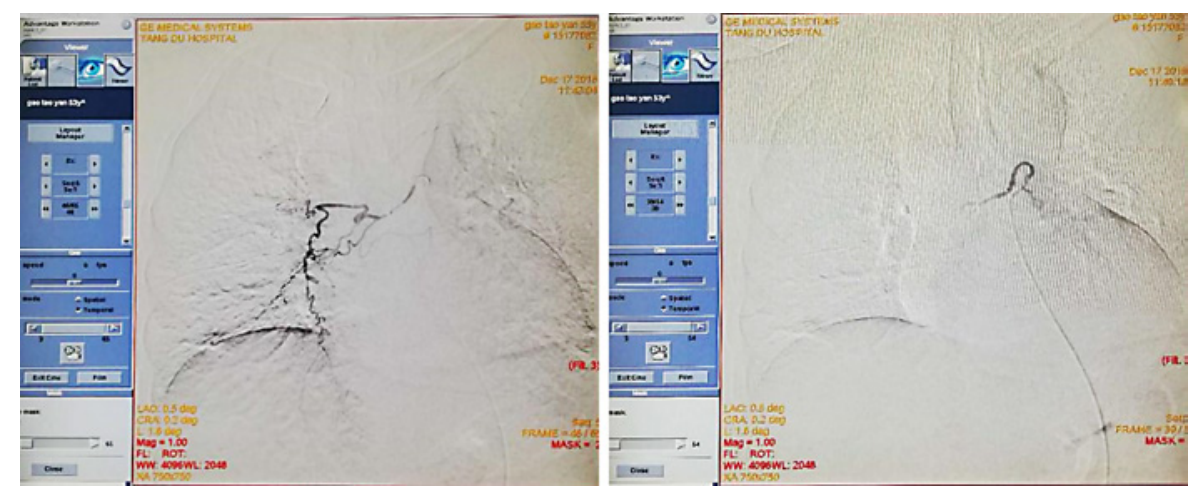

\section{Remove the Blood Clot}

Blood clots formed after massive hemoptysis can block the central airway, leading to hypoxemia or asphyxia. At this time, trying to remove blood clots to improve ventilation is the first consideration. Rigid bronchoscopy or soft bronchoscopy can be used according to the conditions, the rigid bronchoscopy can be used preferentially or combined with soft and rigid bronchoscopy, or soft bronchoscopy can be used under the guidance of tracheal intubation. There are 4 methods: (1) remove blood clots directly: place the front end of the endoscope at the basilar part of the blood clot, pull out the endoscope and remain suctioning, thus giving the opportunity to remove the entire blocked blood clot. (2) Remove blood clots using balloon: place the balloon at the distal end of the central airway clot, then inflate, pull out the endoscope and balloon, and

Expert Recommendation for Diagnosis and Treatment of Massive Hemoptysis remain suctioning when retracting the endoscope. (3) Remove blood clots using machine: blood clots can be removed using biopsy forceps, trigeminal grasping forceps, snares, Dormia basket, and so on (4) remove blood clots by freezing: insert the cryoprobe into the blood clot, start the freezing mode, keep the frozen state, and pull the endoscope body and probe together with the frozen blood clots out of the airway [55], as seen in Figure 4.

Removing the blood clot from the trachea can relieve airway obstruction and improve ventilation. And also, due to the removal of the blood clot and the alleviation of the compression of the bleeding site, the bleeding is caused again. Thus, when removing a blood clot, the operator must be prepared to treat acute massive hemoptysis. For blood clots in the lung lobe, pulmonary segments or side of the bronchi, if there is no life-threatening dys- 
pnea and hypoxemia, the blood clot may not be removed until the bleeding is stabilized.

\section{The Application of Systemic Hemostatic Drugs}

In the case of massive hemoptysis, on the basis of the above treatment measures, systematic hemostatic drugs can be applied at the same time. The choice of hemostatic drugs should be based on the diseases condition and the characteristics of the drug. Commonly used hemostatic drugs are: (1) Pituitrin can reduce peripheral blood flow velocity by contracting visceral arterioles, which is conducive to thrombosis to achieve hemostasis. It can be intramuscular, subcutaneous injection, or diluted intravenous drip. The effect of hemostasis is clear and the taking effect is rapid, but it should be used with caution in patients with hypertension. (2) Hemocoagulase (such as hemocoagulase, hemocoagulase agkistrodon, hemocoagulase bothrops atrox, etc.) exerts a hemostatic effect by promoting the activity of coagulation factors. It can be injected intramuscularly, subcutaneously, intravenously, or locally used under bronchoscopy. Intravenous injection usually takes 5-10 $\mathrm{min}$ to take effect and 20-30 min to reach the peak of hemostasis. The above 2 drugs can be used together in the treatment of massive hemoptysis to enhance the hemostatic effect. (3) Other hemostatic drugs, such as carbazochrome sodium sulfonate, carbazochrome tablets, which acting on the blood vessel wall; hemostatic drugs that acting on platelets, such as etamsylate, platelet suspension; promoting coagulation factor active drugs such as desmopressin acetate; drugs that directly supplement coagulation factors such as fresh or stocked blood, freeze-drying plasma, prothrombin complex; drugs that promote the synthesis of coagulation factors such as vitamin $\mathrm{K}$; antifibrinolytic hemostatic drugs such as 6-aminocaproic acid, aminomethylbenzoic acid, tranexamic acid, and so on. The above drugs or blood products have a weak effect in the first aid for massive hemoptysis, but can be used for subsequent hemostasis treatment. (4) Other drugs used to stop bleeding, such as lidocaine, procaine, phentolamine, 654-2, and other vasodilator drugs, can be used according to the disease.

\section{Follow-Up-Targeted Treatment of Massive}

Hemoptysis

Patients with massive hemoptysis need follow-up targeted treatment after etiological diagnosis and emergency treatment. The current common methods are as follows: (1) bronchial artery embolization
(BAE): BAE is the most commonly used nonsurgical treatment (Fig. 5). BAE should be considered first after initial stabilization of hemoptysis and failure of endoscopic treatment [56-58]. Successful embolization relies on the anatomy of the bleeding vessel by angiography. In patients with continuous and repeated hemoptysis after embolization (6-12 months, 10-20\%), reembolization can be tried to stop bleeding. Late recurrent hemorrhage (more than 1 year) is usually caused by neovascularization or vascular recanalization. In general, BAE is safer and has few complications. However, if intraoperative angiography is ineffective, no communicating branches are found, and spinal cord arteries are misembolized, bronchial wall necrosis and ischemic myeleterosis may occur. (2) Surgical treatment: for patients with unilateral hemorrhage with pulmonary lesions, who cannot stop bleeding through the above various treatment methods, should assess the disease condition and whether the cardiopulmonary function is suitable for surgical intervention as soon as possible, because such patients are prone to occur massive hemoptysis again after temporary hemostasis or BAE treatment. (3) Etiological treatment: when due to some nonanatomical diseases, massive hemoptysis and/or hypoxic respiratory failure, such as DAH caused by massive hemoptysis, at the same time to perform targeted treatment for the relevant etiologies, should provide adequate oxygen delivery by mechanical ventilation or other ancillary treatments. If the patient is suspected to be $\mathrm{DAH}$, high-dose methylprednisolone pulse therapy should be used, and $1 \mathrm{mg} / \mathrm{kg}$ methylprednisolone should be taken orally 3 days later, and 1-2 mg/kg cyclophosphamide should be given at the same time. If the patient is suspected as Goodpasture syndrome, plasma exchange should be conducted to prevent delay in the timing of therapy due to waiting for serological test results $[59,60]$.

In summary, massive hemoptysis is one of emergency and critical diseases of the respiratory system. Patients may die due to asphyxia of airway obstruction or hemorrhagic shock. Therefore, rapid and accurate etiological diagnosis should be carried out, and emergency measures should be taken actively. Before applying BAE or surgical intervention, the airway should be kept unobstructed as early as possible, and multidisciplinary treatment should be carried out to ensure the safety of patients.
90

Respiration 2020;99:83-92 DOI: $10.1159 / 000502156$
Jin/Li/Bai/Wang/Li/Song/Zeng/Zhou/Li/ $\mathrm{Hu} /$ Zhang/Zhou/Zhang 


\section{References}

1 Burke CT, Mauro MA. Bronchial artery embolization. Semin Intervent Radiol. 2004 Mar; 21(1):43-8.

2 Kalva SP. Bronchial artery embolization. Tech Vasc Interv Radiol. 2009 Jun;12(2):130 8.

3 Corey R, Hla KM. Major and massive hemoptysis: reassessment of conservative management. Am J Med Sci. 1987 Nov;294(5):301-9.

4 Noë GD, Jaffé SM, Molan MP. CT and CT angiography in massive haemoptysis with emphasis on pre-embolization assessment. Clin Radiol. 2011 Sep;66(9):869-75.

5 Radchenko C, Alraiyes AH, Shojaee S. A systematic approach to the management of massive hemoptysis. J Thorac Dis. 2017 Sep;9 (Suppl 10):S1069-86

6 Hurt K, Bilton D. Haemoptysis: diagnosis and treatment. Acute Med. 2012;11(1):39-45.

7 Fartoukh M, Khoshnood B, Parrot A, Khalil A, Carette MF, Stoclin A, et al. Early prediction of in-hospital mortality of patients with hemoptysis: an approach to defining severe hemoptysis. Respiration. 2012;83(2):106-14.

8 Hirshberg B, Biran I, Glazer M, Kramer MR. Hemoptysis: etiology, evaluation, and outcome in a tertiary referral hospital. Chest. 1997 Aug;112(2):440-4.

9 Knott-Craig CJ, Oostuizen JG, Rossouw G, Joubert JR, Barnard PM. Management and prognosis of massive hemoptysis. Recent experience with 120 patients. J Thorac Cardiovasc Surg. 1993 Mar;105(3):394-7.

10 Mal H, Rullon I, Mellot F, Brugière O, Sleiman C, Menu Y, et al. Immediate and longterm results of bronchial artery embolization for life-threatening hemoptysis. Chest. 1999 Apr;115(4):996-1001.

11 Ong TH, Eng P. Massive hemoptysis requiring intensive care. Intensive Care Med. 2003 Feb;29(2):317-20.

12 Lee TW, Wan S, Choy DK, Chan M, Arifi A, Yim AP. Management of massive hemoptysis: a single institution experience. Ann Thorac Cardiovasc Surg. 2000 Aug;6(4):232-5.

13 Jean-Baptiste E. Clinical assessment and management of massive hemoptysis. Crit Care Med. 2000 May;28(5):1642-7.

14 Jiang S. Human sectional anatomy. People's Medical Publishing House. PMPH; 2008. p. 109.

15 Zhang Y, Chen C, Jiang GN. Surgery of massive hemoptysis in pulmonary tuberculosis: immediate and long-term outcomes. J Thorac Cardiovasc Surg. 2014 Aug;148(2):651-6.

16 Gupta K, Saggar K, Goyal A, Banerjee A Anomalies of Pulmonary Circulation as a Cause of Hemoptysis: A Series of Unusual Cases and Review of the Literature. Oman Med J. 2015 May;30(3):208-11.
17 Kokkonouzis I, Athanasopoulos I, Doulgerakis N, Tsonis G, Lampaditis I, Saridis N, et al. Fatal Hemoptysis due to Chronic Cavitary Pulmonary Aspergillosis Complicated by Nontuberculous Mycobacterial Tuberculosis. Case Rep Infect Dis. 2011;2011:837146.

18 Sabayev V, Savel RH, Schiteanu A, Asnis D, Veloudios A. Invasive Aspergillosis-Associated Pulmonary Artery Pseudoaneurysm: A Rare Cause of Hemoptysis in an HIV-Infected Patient. Clin Pulm Med. 2005;12(5):297300.

19 Caulet S, Capron F, Laaban JP, Prudent J, Rochemaure J, Diebold J. [Fatal hemoptysis during bronchial aspergillosis with multiple pulmonary artery aneurysms]. Ann Pathol. 1990; 10(3):177-80

20 Feng J, Sun X. Characteristics of pulmonary mucormycosis and predictive risk factors for the outcome. Infection. 2018 Aug;46(4):50312.

21 Brown RB, Johnson JH, Kessinger JM, Sealy WC. Bronchovascular mucormycosis in the diabetic: an urgent surgical problem. Ann Thorac Surg. 1992 May;53(5):854-5.

22 Lee FY, Mossad SB, Adal KA. Pulmonary mucormycosis: the last 30 years. Arch Intern Med. 1999 Jun;159(12):1301-9.

23 Paya CV. Fungal infections in solid-organ transplantation. Clin Infect Dis. 1993 May; 16(5):677-88

24 Albelda SM, Talbot GH, Gerson SL, Miller WT, Cassileth PA. Pulmonary cavitation and massive hemoptysis in invasive pulmonary aspergillosis. Influence of bone marrow recovery in patients with acute leukemia. Am Rev Respir Dis. 1985 Jan;131(1):115-20.

25 Carteaux G, Contou D, Voiriot G, Khalil A, Carette MF, Antoine M, et al. Severe Hemoptysis Associated with Bacterial Pulmonary Infection: Clinical Features, Significance of Parenchymal Necrosis, and Outcome. Lung. 2018 Feb;196(1):33-42.

26 Miller RR, McGregor DH. Hemorrhage from carcinoma of the lung. Cancer. 1980 Jul;46(1): 200-5.

27 Goto K, Endo M, Kusumoto M, Yamamoto N, Ohe Y, Shimizu A, et al. Bevacizumab for non-small-cell lung cancer: A nested case control study of risk factors for hemoptysis. Cancer Sci. 2016 Dec;107(12):1837-42.

28 Zandman-Goddard G. Diffuse alveolar hemorrhage in autoimmune diseases. Isr Med Assoc J. 2002 Jun;4(6):461-2.

29 Cheng S, Lu X, Wang J, Liu T, Zhang X. Thoracoscopic lobectomy for massive hemoptysis caused by complete pulmonary vein occlusion after radiofrequency ablation for atrial fibrillation. J Thorac Dis. 2018 Apr;10(4): E296-300.

30 Zhang G, Yu H, Chen L, Li Y, Liang Z. Pulmonary veins stenosis after catheter ablation of atrial fibrillation as the cause of haemoptysis: three cases and a literature review. Clin Respir J. 2018 Jan;12(1):3-9.
31 Tellapuri S, Park HS, Kalva SP. Pulmonary arteriovenous malformations. Int J Cardiovasc Imaging. 2019 Aug;35(8):1421-8.

32 Mall S, Sharma RK, Prajapat D, Gupta SK, Talwar D. Hemoptysis: beyond routine chest computed tomography and bronchoscopy. Lung India. 2017 Jul-Aug;34(4):368-71.

33 Kim H, Kwon D, Yoon SH, Kim H, Park CM, Goo JM, et al. Bronchovascular injury associated with clinically significant hemoptysis after CT-guided core biopsy of the lung: Radiologic and histopathologic analysis. PLoS One. 2018 Sep;13(9):e0204064.

34 Wang Y, Jiang F, Tan X, Tian P. CT-guided percutaneous transthoracic needle biopsy for paramediastinal and nonparamediastinal lung lesions: diagnostic yield and complications in 1484 patients. Medicine (Baltimore). 2016 Aug;95(31):e4460.

35 Zhang S, Zheng Y, Yu P, Yu F, Zhang Q, Lv Y, et al. The combined treatment of CT-guided percutaneous $125 \mathrm{I}$ seed implantation and chemotherapy for non-small-cell lung cancer. J Cancer Res Clin Oncol. 2011 Dec;137(12): 1813-22.

36 Zhu JC, Yan TD, Glenn D, Morris DL. Radiofrequency ablation of lung tumors: feasibility and safety. Ann Thorac Surg. 2009 Apr;87(4): 1023-8.

37 Sano Y, Toyooka S, Okabe K, Aoe M, Date H, Mukai T, et al. O-144 Feasibility of the percutaneous radiofrequency ablation (RFA) for intrathoracic malignancies. Lung Cancer. 2005;49 Suppl 2:S49.

38 Siobal M, Kallet RH, Kraemer R, Jonson E, Lemons D, Young D, et al. Tracheal-innominate artery fistula caused by the endotracheal tube tip: case report and investigation of a fatal complication of prolonged intubation. Respir Care. 2001 Oct;46(10):1012-8.

39 Friduss M, Hoover LA, Alessi D, Robertson J. Traumatic innominate pseudoaneurysm rupture during laryngeal dilatation. Ann Otol Rhinol Laryngol. 1987 Nov-Dec;96(6):695-7.

40 Madden BP. Evolutional trends in the management of tracheal and bronchial injuries. J Thorac Dis. 2017 Jan;9(1):E67-70.

41 Broderick SR. Hemothorax: Etiology, diagnosis, and management. Thorac Surg Clin. 2013 Feb;23(1):89-96.

42 Mo XD, Xu LP, Liu DH, Zhang XH, Chen H, Chen YH, et al. High-dose cyclophosphamide therapy associated with diffuse alveolar hemorrhage after allogeneic hematopoietic stem cell transplantation. Respiration. 2013;86(6): 453-61.

43 Coucke L, Marcelis L, Deeren D, Van Dorpe J, Lambein K, Devreese K. Lymphoplasmacytic lymphoma exposed by haemoptysis and acquired von Willebrand syndrome. Blood Coagul Fibrinolysis. 2014 Jun;25(4):395-7.

44 Padhi P, Parihar G, Stepp J, Kaplan R. Posttransfusion purpura: a rare and life-threatening aetiology of thrombocytopenia. BMJ Case Rep. 2013 May;2013:pii:bcr2013008860.
Expert Recommendation for Diagnosis and Treatment of Massive Hemoptysis 
45 Cartoni C, Niscola P, Breccia M, Brunetti G, D'Elia GM, Giovannini M, et al. Hemorrhagic complications in patients with advanced hematological malignancies followed at home: an Italian experience. Leuk Lymphoma. 2009 Mar;50(3):387-91.

46 Khalil A, Soussan M, Mangiapan G, Fartoukh M, Parrot A, Carette MF. Utility of high-resolution chest CT scan in the emergency management of haemoptysis in the intensive care unit: severity, localization and aetiology. $\mathrm{Br} \mathrm{J}$ Radiol. 2007 Jan;80(949):21-5.

47 Sakr L, Dutau H. Massive hemoptysis: an update on the role of bronchoscopy in diagnosis and management. Respiration. 2010;80(1): 38-58.

48 Yoon W, Kim JK, Kim YH, Chung TW, Kang HK. Bronchial and nonbronchial systemic artery embolization for life-threatening hemoptysis: a comprehensive review. Radiographics. 2002 Nov-Dec;22(6):1395-409.
49 Colchen A, Fischler M. [Emergency interventional bronchoscopies]. Rev Pneumol Clin. 2011 Sep;67(4):209-13.

50 Ittrich H, Bockhorn M, Klose H, Simon M. The Diagnosis and Treatment of Hemoptysis. Dtsch Arztebl Int. 2017 Jun;114(21):371-81.

51 Rali P, Gandhi V, Tariq C. Massive hemoptysis. CritCare Nurs Q.2016Apr-Jun;39(2):139_ 47.

52 Haponik EF, Fein A, Chin R. Managing lifethreatening hemoptysis: has anything really changed? Chest. 2000 Nov;118(5):1431-5.

53 Earwood JS, Thompson TD. Hemoptysis: evaluation and management. Am Fam Physician. 2015 Feb;91(4):243-9.

54 Shigemura N, Wan IY, Yu SC, Wong RH, Hsin MK, Thung HK, et al. Multidisciplinary management of life-threatening massive hemoptysis: a 10-year experience. Ann Thorac Surg. 2009 Mar;87(3):849-53.

55 Sehgal IS, Dhooria S, Agarwal R, Behera D. Use of a Flexible Cryoprobe for Removal of Tracheobronchial Blood Clots. Respir Care. 2015 Jul;60(7):e128-31.
56 Gupta A, Sands M, Chauhan NR. Massive hemoptysis in pulmonary infections: bronchial artery embolization. J Thorac Dis. 2018 Oct; 10(S28 Suppl 28):S3458-64.

57 Bin Sarwar Zubairi A, Tanveer-ul-Haq, Fatima K, Azeemuddin M, Zubairi MA, Irfan M. Bronchial artery embolization in the treatment of massive hemoptysis. Saudi Med J. 2007 Jul;28(7):1076-9.

58 Panda A, Bhalla AS, Goyal A. Bronchial artery embolization in hemoptysis: a systematic review. Diagn Interv Radiol. 2017 Jul-Aug; 23(4):307-17.

59 Nasser M, Cottin V. Alveolar Hemorrhage in Vasculitis (Primary and Secondary). Semin Respir Crit Care Med. 2018 Aug;39(4):48293.

60 Casal A, Díaz-Garel J, Pereiro T, Toubes ME, Ricoy J, Valdés L. Pulmonary vasculitis. J Thorac Dis. 2018 Sep;10(9):5560-75. 